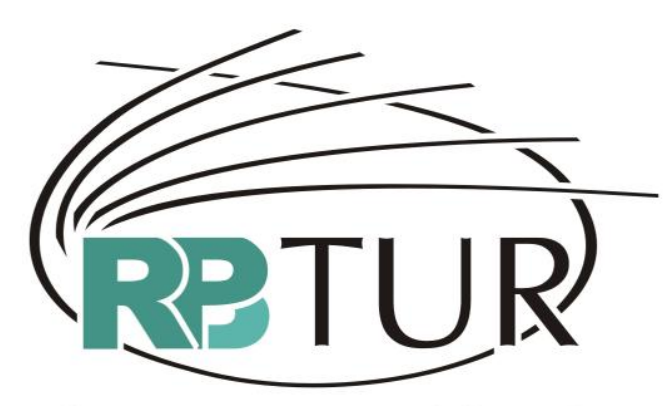

REVISTA BRASILEIRA DE PESQUISA EM TURISMO

\title{
COMUNIDADES E SEUS ARRANJOS PRODUTIVOS NO TURISMO DO ESTADO DO CEARÁ
}

\author{
COMMUNITY AND PRODUCTION ARRANGEMENTS FOR \\ TOURISM AT CEARA STATE, BRAZIL
}

\section{COMUNIDAD Y ARREGLOS PRODUCTIVOS EN TURISMO EN EL ESTADO DE CEARÁ, BRASIL}

Ricardo de Oliveira Rezende ${ }^{1}$

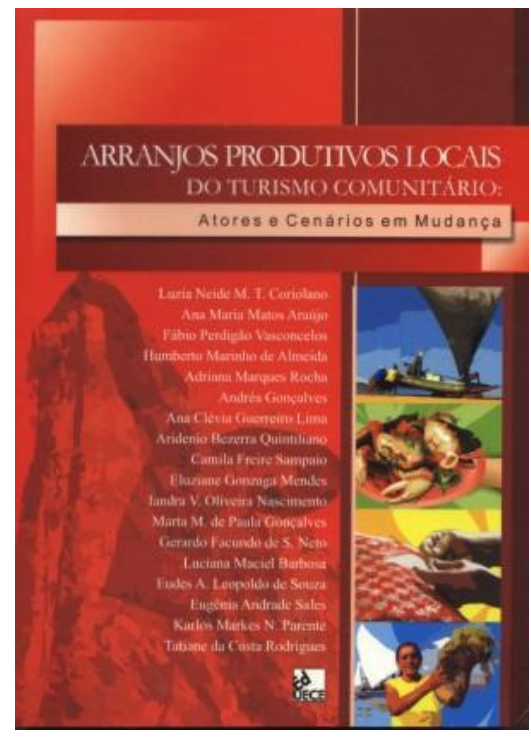

CORIOLANO, Luzia Neide M. T. et al. Arranjos produtivos locais do turismo comunitário: atores e cenários em mudança. Fortaleza: Ed. UECE, 2009. 312 p. ISBN: 978-85-7826-031-6

Esta obra é resultado do trabalho de alunos, professores e pesquisadores do Mestrado Acadêmico em Geografia (MAG) da Universidade Estadual do

1 Mestrando em Estudos Populacionais e Pesquisas Sociais - Escola Nacional de Ciências Estatísticas (ENCE/IBGE). E-mail: ricarduus@gmail.com 
Ceará (UECE) ${ }^{2}$. Com esta obra o MAG consolida sua tradição no estudo crítico do desenvolvimento do turismo no estado do Ceará. A pesquisa feita pelo Grupo de Pesquisa "Turismo, Território e Cultura", no âmbito do Laboratório de Estudos do Território e do Turismo (NETTUR), analisa, sob o ponto de vista da Geografia, o turismo e a hospitalidade que se desenvolvem comunitariamente naquele estado.

Inicialmente, colocam que o turismo e a hospitalidade alternativos do Ceará, apresentam dois movimentos: 1) um, que envolve lugares e pessoas periféricos aos circuitos econômicos globalizados que buscam se inserir no trade com a oferta de serviços alternativos consubstanciando o chamado "circuito inferior"; 2) outro, complementar ao primeiro, parte de turistas, chamados "conscientes", que refutando a moda e os modismos, buscam conhecer lugares menos urbanizados e fazer um turismo diferenciado ${ }^{3}$.

As comunidades cearenses têm mostrado, segundo os autores, que são capazes de se adaptar ao modelo pós-fordista de produção dentre outras estratégias, se organizando produtivamente em arranjos produtivos locais de base comunitária (APLBC), forma que se situa no rol das novas estratégias de desenvolvimento local (cluster, arranjo produtivo local - APL, etc.). No entanto, os APLBCs se diferenciam dos APLs por serem núcleos produtivos improvisados e com aglomerações de empresas com organização social e institucional em estágio ainda muito rudimentar.

Dados do Centro de Estratégias de Desenvolvimento (CED/CE) mostram que existem vários APLs com empresas de médio porte ligados a setores com alto potencial de desenvolvimento local, no entanto, grande parte dos APLs encontram-se em estágio embrionário, apresentando modesto capital social, ambiente de desconfiança, concorrência contraproducente e mínima capacidade inovadora com limitações competitivas locais. Os APLs do turismo

2 A pesquisa foi financiada pelo Conselho Nacional de Desenvolvimento Científico e Tecnológico (CNPq).

3 Vale citar que em países europeus, como a Itália, existem agências de viagem especializadas nas chamadas viaggi consapevoli ou viagens conscientes, onde o turista não só adquire conhecimento ex ante, acerca dos lugares que visitará, como é chamado a contribuir com projetos sociais e comunitários dos destinos. 
no Ceará ${ }^{4}$, segundo os autores, encontram-se obstaculizados pela massificação concentrada em alguns destinos litorâneos e não encontram apoio do poder público, cujo entendimento da atividade turística é de exagerado otimismo na superação do desenvolvimento insuficiente através de megaprojetos.

$\mathrm{Na}$ medida em que se acelera a retração do mercado formal e o crescimento da economia informal, milhares de pessoas são levadas a empreender, podendo-se dizer, então, que há empreendedores por necessidade e por oportunidade. A estratégia dos APLs não pode dar conta das mudanças na economia e não cobrem a enorme dívida social brasileira, sendo que se disseminou como modismo.

Os APLBC são arranjos produtivos alternativos, informais e solidários que se dão em pequenas comunidades, bairros ou grupos e são estratégias de sobrevivência que abrangem a hospitalidade juntamente com outras atividades. Comunidade nesta obra é grupo social residente em pequeno espaço geográfico, cuja interação e integração de pessoas entre si e destas com o lugar é fortíssima. Comunidade e lugar são conceitos equivalentes, sendo o primeiro termo mais usado na antropologia e o segundo na geografia. A solidariedade seria o elemento principal da comunidade, entendida como paraíso perdido em que cabe individualidade, não individualismo.

O turismo encontrou a economia solidária em oposição ao "turismo dos resorts e dos megaempreendimentos" cujo poder viabiliza até de construir em áreas legalmente protegidas do litoral. O litoral nordestino no processo de reestruturação capitalista do espaço foi valorizado através do turismo e do lazer, o que fez do litoral, a principal mercadoria imobiliária. Mas, o turismo nas comunidades tem interferido nas atividades tradicionais e nem sempre apresenta resultados satisfatórios.

Procurando entender a política pública para o turismo no estado, analisam a atuação dos governos. Identificam um duplo padrão na ação estatal no Ceará, corroborando a teoria de Boaventura Sousa Santos, para quem há uma crise que afeta o contrato social dos países periféricos do capitalismo. 
Esta crise se mostra dentre outras formas na existência, de um fascismo estatal onde existe um duplo padrão da ação estatal: uma para as zonas selvagens (fora do contrato) e outra para as zonas "civilizadas". ${ }^{5}$

A gestão neoliberal se mostra tanto interventora como liberal de acordo com as suas conveniências pragmáticas. Mas é na atuação sobre as questões sociais que a política neoliberal se esvai, deixando de atuar sobre elas. Atividades econômicas como o turismo, por sua vez, são privilegiadas em termos de apoio institucional, o que é uma contradição no acerto na proporção das políticas públicas, já que falamos de um dos estados mais pobres do Brasil. Os órgãos públicos revelam grande generosidade com as empresas em geral, fornecendo infra-estrutura e isenção de impostos como forma de incentivo fiscal, ignorando inclusive a baixa absorção de trabalhadores e os baixos salários aplicados.

O processo de regionalização do turismo no Ceará tem o vício de privilegiar as áreas litorâneas em detrimento do interior do estado. Sendo assim, a "Turística Fortaleza" (Região Metropolitana), a "Costa do Sol Poente" (litoral a oeste de Fortaleza) e a "Costa do Sol Nascente" (litoral a leste de Fortaleza) são as regiões turísticas que justificam as expectativas no turismo. Mas, ao largo das políticas públicas vêm surgindo em todo o estado iniciativas de turismo comunitário, que não interessam aos órgãos oficiais, pois não se voltam especialmente para o mercado.

Afirmam que a inserção de grupos investidores europeus, notadamente portugueses e espanhóis, com a implantação de hotéis e resorts, é reflexo da onda de investimentos pós-SUDENE. No entanto, mesmo com tal monta de investimentos, não podem ser confundidas como desenvolvimento, pois não beneficiam o povo, o Nordeste é ainda uma das regiões brasileiras onde a pobreza é maior. ${ }^{6}$

O turismo no Nordeste só pode ser entendido como coadjuvante do

5 SANTOS, Boaventura de Sousa. Reinventar a Democracia: entre o pré-contratualismo e póscontratualismo. In: HELLER, Agnes, et al. A crise dos paradigmas em ciências sociais e os desafios para o século XXI. Rio de Janeiro: Contraponto, 1999, p. 33-75.

6 Afirmam os autores "o projeto capitalista de modernização dos espaços, voltado para as elites, não pode ser confundido com desenvolvimento" (CORIOLANO, 2009, p. 102). 
desenvolvimento econômico e não como setor-chave, posto que o comércio e os serviços têm sua estruturação e dinamismo induzidos pelo que se passa na indústria, ou seja, suas características estão fortemente influenciadas pela dinâmica industrial.

No Nordeste o produto turístico mais comercializado é o de modelo "sol e praia", no qual os resorts ${ }^{7}$ existem como enclaves nas comunidades onde se instalam, pois utilizam uma variedade de estratégias para reter ao máximo o turista, isolando-o da realidade ao redor. Denominados "paradisíacos", com clientes de alto poder aquisitivo, os resorts não contribuem para o desenvolvimento local. $E$, em detrimento de terem disponibilizadas infraestruturas e isenções, com dinheiro público, não thes são exigidas contrapartidas substanciais. O turismo não empregou o suficiente para ocupar a mão-de-obra subocupada e desempregada e, o mais grave, concedeu incentivos fiscais sem exigir compromissos para com os lugares e as pessoas que ali habitam.

Adicionalmente, apresentam resultados de uma pesquisa feita pelo MAG acerca dos pequenos empreendimentos de hospedagem localizados em Fortaleza (com até 50 unidades habitacionais - UHs). Os dados mostram que a política pública precisa atuar no sentido de apoiar também os empreendimentos urbanos informais. Trata-se de mais um reforço na ideia de que as políticas públicas têm que se voltar aos pequenos empreendimentos, sejam urbanos ou rurais, litorâneos ou rurais.

A chegada do turismo nas comunidades cearenses se deu em três estágios: primeiro, a chegada dos mochileiros desbravadores nos anos 1970; segundo, o veraneio relacionado com as segundas residências nos anos 1980, que corresponde ao primeiro avanço capitalista sobre o litoral, consolidado nos anos 1990, com a chegada dos investimentos diretos do turismo com o PRODETUR/CE; terceiro, o estágio atual, alguns outrora turistas vêm se estabelecer como empreendedores do turismo.

7 Os autores conceituam os resorts como "meios de hospedagem com configurações espaciais elitizadas, localizadas preferencialmente em áreas naturais preservadas, e muitas vezes, distantes de áreas urbanizadas" (CORIOLANO, 2009, p. 104). 
É neste contexto que comunidades resistem à tomada de seus territórios pelos empreendedores turísticos e imobiliários, organizando-se em movimentos de resistência, procurando se inserir num outro eixo de turismo que é aquele não oligopolizado, não colonizado, de base local, com arranjos produtivos de base comunitária.

Os autores afirmam que esta nova forma de entendimento e empreendimento do turismo atende a uma demanda específica que congrega grupos de pesquisadores, famílias simples e turistas europeus. Descrevem algumas experiências alternativas de turismo comunitário no Ceará: a hospedagem familiar no município de Icapuí, as expectativas das rendeiras de Almofala, Flecheiras e Aquiraz, as cooperativas dos bugueiros de Caucaia, a experiência já bastante estudada da Prainha do Canto Verde, que recentemente foi estabelecida como reserva extrativista (RESEX), o cultivo sustentado de algas em Flecheiras e Guajiru, a comunidade em conflito com o grande capital do turismo em Tatajuba, o Centro das Tapioqueiras e de Artesanato de Messejana, o de turismo dos negócios populares na Feira do Beco da Poeira em Fortaleza, o Conjunto Palmeira e as finanças solidárias, as potencialidades do espaço rural de Tejuçuoca para o turismo e o turismo cultural e pedagógico em Nova Olinda.

Para concluir, destacam que as experiências estudadas constituem um convite para se fazer uma revolução no modo de viver, de produzir e de fazer turismo, colocando que é preciso situar o turismo dentre aquelas atividades que levem em conta também as periferias, as necessidades dos pobres e dos grupos excluídos. O desenvolvimento é um conceito criado pelas nações hegemônicas a fim de explicar as desigualdades sem entrar no verdadeiro cerne da questão. Para se alcançar o verdadeiro desenvolvimento faz-se necessária a produção de riqueza com justiça social, princípios de equidade e respeito aos direitos humanos. Afirmam, para finalizar, que os APLBCs diferem radicalmente dos APLs implementados no Brasil, pois se contrapõem ao modelo de desenvolvimento hegemônico. 